\title{
Drivers of Airbnb prices according to property/room type, season and location: A regression approach
}

\author{
Augusto Voltes-Dorta ${ }^{\mathrm{a}, *}$, Agustín Sánchez-Medina ${ }^{\mathrm{b}}$ \\ ${ }^{a}$ University of Edinburgh Business School, Management Science and Business Economics Group, EH8 9JS, Edinburgh, United Kingdom \\ ${ }^{\mathrm{b}}$ Departamento de Economía y Dirección de Empresas (DEDE), Universidad de Las Palmas de Gran, Canaria, Spain
}

\section{A R T I C L E I N F O}

\section{Keywords:}

Accommodation pricing

Airbnb

Sharing economy

Geographically-weighted regression

\begin{abstract}
A B S T R A C T
While past studies on Airbnb pricing highlight the importance of room features, host characteristics and location factors, little has been investigated about whether these factors are the same across different property/room types, locations and seasons. To fill that gap, this paper presents a study about the drivers of Airbnb prices in Bristol using ordinary least squares (OLS) and geographically-weighted regression (GWR) methods. The estimated models exhibit sharply different levels of goodness-of-fit, suggesting that the prices of different room types might not be explained by the same set of price factors. The results also uncover statistically significant differences between the price determinants of apartments and house listings and reveal spatial patterns in the price effects. These findings have implications for price setting and the assessment of competition. Future studies should account for potential differences across property/room types, as well as to consider the spatial variability of the estimated coefficients.
\end{abstract}

\section{Introduction}

Since 2008, Airbnb has penetrated the short-term accommodation markets of many large and medium-size cities all over the world, and it is already a major source of competition to hotels and other accommodation providers (Dogru et al., 2019). Since hosts are responsible for pricing their own listed properties, the analysis of which factors affect Airbnb rates has been of great relevance to both academics and practitioners. Building upon past studies on hotel pricing and its determinants, Airbnb-specific contributions have employed regression methods to test the impact of room and host characteristics (Chen \& Xie, 2017), quality signals and customer ratings (Lawani et al., 2019), as well as locational characteristics, such as the distance to the city-centre or tourism hotspots (Gunter \& Önder, 2018).

In spite of the above, little has been investigated about whether these factors are the same across different property/room types, seasons and locations. Since different Airbnb property types might target different visitor segments (Lutz \& Newlands, 2018), we hypothesize that the actual price impacts differ according to the type of listing (i.e. entire home vs private room, apartment vs houses). We investigate this issue in a higher level of detail than past studies by separating our sample according to both property and room type to reach more detailed conclusions. A second research gap appears in relation to the analysis of seasonal pricing. Even though past papers have already shown that, similarly to hotels, Airbnb hosts are implementing dynamic pricing strategies to boost their revenues (Magno et al., 2018), the literature still lacks studies that compare the impact of the price factors between peak and off-peak periods. Results can be of relevance to Airbnb hosts to tailor their pricing strategies to the specific characteristics of their properties.

To tackle the points above, this paper presents a case study about the drivers of Airbnb prices in Bristol (United Kingdom). Using a publicly-available dataset of Airbnb listings complemented with information on local points of interest, we employ both ordinary least squares (OLS) and geographically-weighted regression (GWR) approaches to estimate a set of hedonic price equations. Past studies concluded that GWR has superior accuracy than OLS models due to its ability to capture spatial variability of price effects across different areas (e.g. neighbourhoods) within the city-wide markets.

The remainder of this paper is structured as follows: Section 2 provides a literature review about the drivers of demand for Airbnb prices. Section 3 presents the Bristol case study, covers the process of data collection and processing, as well as the different regression approaches. Section 4 presents the results and discusses their main implications. Section 5 concludes with a summary of the main findings.

\footnotetext{
* Corresponding author.

E-mail address: avoltes@becarios.ulpgc.es (A. Voltes-Dorta).
} 


\section{Literature review}

During the last decade, Airbnb has become the flagship platform in the peer-to-peer accommodation market by allowing property owners to list their properties to prospective guests in direct competition to traditional accommodation providers. As such, Airbnb presence is shown to have a penetrative effect in hotel markets (Xie \& Kwok, 2017), which may translate into a reduction in revenues and occupancy rates in both high-end and low-end hotel segments (Dogru et al., 2019). On the other hand, some authors argue that the sharing economy platform has a complementary effect in hotel markets (Blal et al., 2018), as the extended accommodation offering brings more visitors to the respective cities.

Considering that Airbnb hosts can set the prices for their own properties on the platform, it is not surprising that there is plenty of recent literature on the analysis of Airbnb price determinants. These studies typically employ econometric methods (such as OLS) to estimate hedonic price equations, with the selection of explanatory variables being well rooted on the broader econometric literature on hotel prices, including: 1) room features and other amenities, such as room size, Wi-Fi, TV, or a gym (Schamel, 2012; Chen and Rothschild, 2010); 2) quality signals, such as the hotel's brand, star rating, or customer reviews (Becerra et al., 2013; Masiero et al., 2015; Schamel, 2012; Yang et al., 2016); and 3) locational aspects, such as the proximity to city centre and other tourism hotspots. Proximity is typically expected to increase hotel prices (Soler \& Gemar, 2018), but it is also possible to have cheaper hotels in downtown locations due to increased spatial competition in comparison with outskirts providers (Chen \& Rothschild, 2010).

The econometric literature on Airbnb prices displays a broader choice of price determinants. As expected, the features of the listed room or property are the most commonly-analysed explanatory variables, including the number of beds, bedrooms, or bathrooms, which are typically found to affect prices (e.g. Chen \& Xie, 2017; Gibbs et al., 2018; Gunter \& Önder, 2018; Lorde el al., 2019). Host characteristics, such as reputation or "superhost" status (Chen \& Xie, 2017; Magno et al., 2018), responsiveness (Gunter \& Önder, 2018) or experience (Zhang et al., 2017) can be statistically significant price drivers as well. Also rental rules (Lawani et al., 2019) and customer feedback, as prices can be influenced by customer ratings and review comments (Kwok \& Xie, 2019). In regards to location, most studies consider the distance to city centre (Gunter \& Önder, 2018), transport points (Magno et al., 2018), coastline (Perez-Sanchez et al., 2018) and/or other points of interest such as sightseeing, nightlife or retail hotspots (Magno et al., 2018; Perez-Sanchez et al., 2018). Another spatial element relates to the proximity to traditional accommodation providers and even to other Airbnb properties. In relation to this, past studies include a measurement of average hotel prices around each listing (Magno et al., 2018; Önder et al., 2018), as well as the number of competing Airbnbs in the same neighbourhood, which can have either detrimental of complementary effects on rates (Lawani et al., 2019).

While these studies highlight the importance of room/property features, host characteristics, and location factors, little has been investigated about whether the impact of these factors on prices is the same across different property and room types. Most of the studies mentioned above indeed account for the fact that their listing datasets include different property types (mostly apartments and houses) as well as different room types (entire homes, private rooms or shared rooms). However, estimation samples are always pooled, and the property/ room type effects have been always incorporated as dummy variables that only shift the intercepts of their regression models (e.g. Chattopadhyay \& Mitra, 2020; Chen \& Xie, 2017; Kwok \& Xie, 2019; Tong \& Gunter, 2020). Unsurprisingly, room dummies are always negative and statistically significant as room prices tend to be lower than entire property prices (Gibbs et al., 2018). Only Wang and Nicolau (2017) crossed these dummies with the country of the listing, but still, no further interactions between these dummies and the room, host, or location factors were specified.

Against that simplified approach of past studies, we note that different Airbnb property types have been already shown to target different visitor segments. For example, Lutz and Newlands (2018) established differences in terms of income, age, group size and social interaction between the targeted guests in entire homes and private rooms. The income differences, in particular, beg the question of whether the willingness to pay for additional room features (and thus the price impacts that econometric regressions aimed to quantify) is the same across users. Therefore, we hypothesize that the actual price impacts differ according to the type of listing. To date, only the recent paper by Lopez et al. (2020) investigated Airbnb prices with separate equations for room types, finding statistically significant differences in the price effects of several room, host and location features. We investigate this issue in a higher level of detail than past studies by disaggregating our sample further according to both property and room types to reach more detailed conclusions.

A second research gap appears in relation to the analysis of seasonal pricing. Magno et al. (2018) concluded that Airbnb rates in Verona (Italy) increase with the overall market demand, and thus, they adjust to seasonal fluctuations in the number of visitors to the city. Thus, it is clear that Airbnb hosts are implementing dynamic pricing strategies to boost their revenues. However, similarly to the case above, the literature still lacks studies that compare the impact of the price factors between peak and off-peak periods. Again, the hypothesis that the respective regression coefficients may differ according to season can be rooted in the well-established notion that travel purpose (and thus, visitor segments) also exhibit marked seasonal patterns, with the bulk of leisure travellers arriving during the summer months.

Disaggregated price effects according to property/room type and season can be of relevance to Airbnb hosts to tailor their pricing strategies to the specific characteristics of their listings and the time period in which they are in the market.

From a methodological perspective, it is worth noting that the use of global regression approaches (such as OLS) leads to hedonic price equations with fixed coefficients at a city level. Thus, the sensitivity of prices to the different predictors remains constant across neighbourhoods. There is evidence, however, that this may be an oversimplification of the behaviour of Airbnb prices given the clear spatial patterns identified by the literature, which point to central areas and tourist hotspots having a much higher density of listings and competition than more peripheral areas (Boros et al., 2018; Dudás et al., 2017; Eugenio-Martín et al., 2019). In relation to this, the broader literature on the determinant of house prices features many studies that employ the geographically-weighted regression (GWR) approach (e.g. Fotheringham et al., 2015; Mccord et al., 2012; Yao \& Fotheringham, 2016). This method carries out a linear regression for each individual location, in which all other sample locations are weighted inversely according to distance. This way, the GWR delivers regression coefficients that are location-specific, which allows the researcher to uncover spatial patterns in the relevant price effects. To date, there are only few applications of GWR to study accommodation prices. Soler and Gemar (2018) employed GWR to estimate a series of hedonic price models for a sample of Spanish hotels and concluded that, while linear models are accurate in determining the sign of the relevant interactions, ignoring the geographic variability of the model coefficients may lead to misleading results. To the best of our knowledge, only Zhang et al. (2017) and Suárez-Vega and Hernández (2020) employ GWR to model Airbnb prices, both concluding that the spatially-weighted regression has superior accuracy than the linear model. An interesting conclusion that illustrates the added value of GWR is that prices can be more sensitive to the distance from the city centre the more centrally-located the listing is (Zhang et al., 2017). Still, with this scarce body of literature, by employing a GWR approach in our analysis we aim to provide confirmatory evidence about the spatial variability of Airbnb price determinants disaggregated by season and property/room type. 


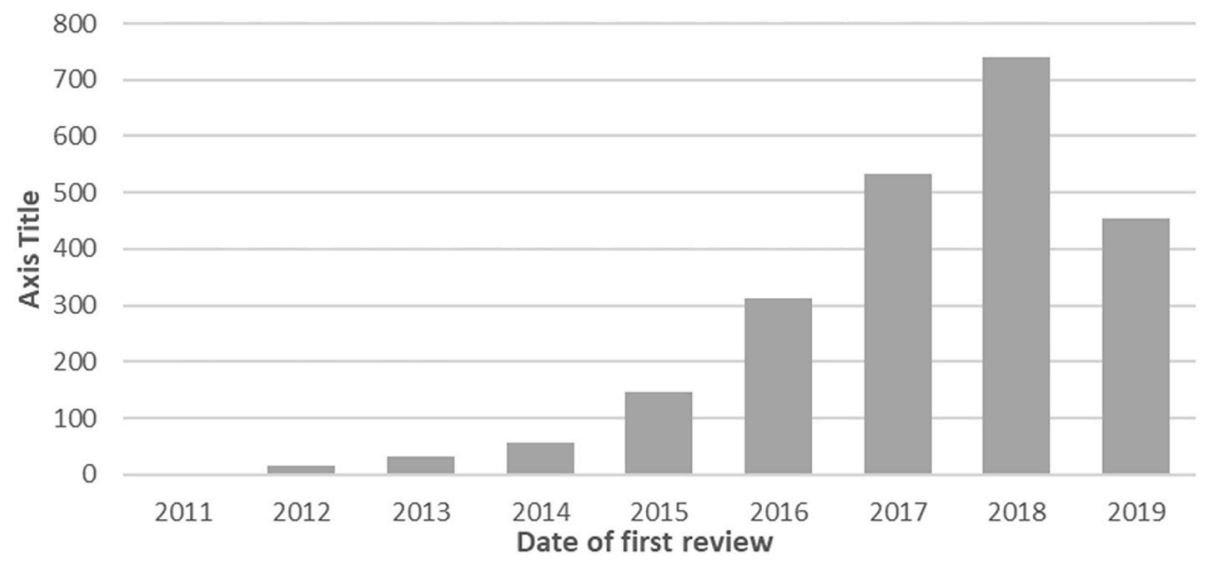

Fig. 1. Dates of first review for extant Airbnb listings in Bristol (July 2019).

Source: www.insideairbnb.com

\section{Data and methodology}

\subsection{Case study and datasets}

Located in the South West of England, beside the river Avon, Bristol is within the top-ten most populated cities in the UK, as well as one of its top tourist destinations. The presence of Airbnb in Bristol can be traced back to 2011 (Fig. 1) and has developed exponentially ever since (based on the first review dates of extant listings). This has prompted the protest of local hotel companies, which see this platform for shortterm tourism rentals as having an unfair competitive advantage in terms of taxes and regulatory requirements such fire and other safety standards (ITV, 2018). These claims are usually addressed by Airbnb by referring to the more diverse and price-competitive accommodation offering, as well as the benefits for local owners that can obtain higher profits by renting their properties to visitors and tourists via their platform, as opposed to the medium- or long-term residential market. Hosts are in charge of the pricing of their own properties and, after paying a fee to the Airbnb platform, they retain the proceeds.

Fig. 2 shows the monthly distribution and average prices for entire homes and private rooms listed on Airbnb in Bristol between September

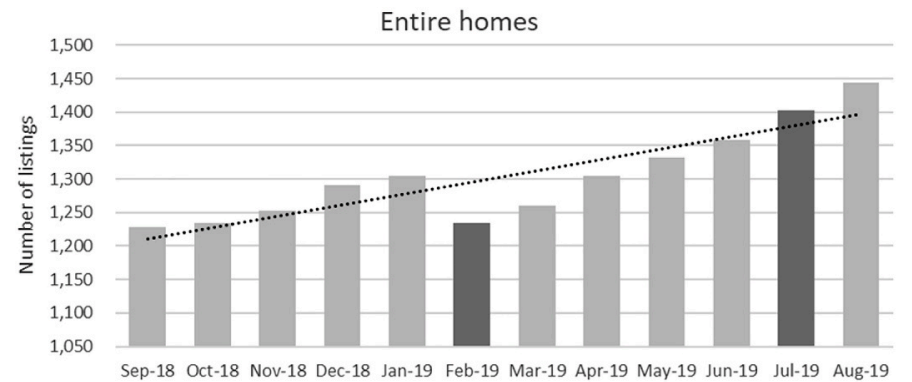

Entire homes: avg. price per night

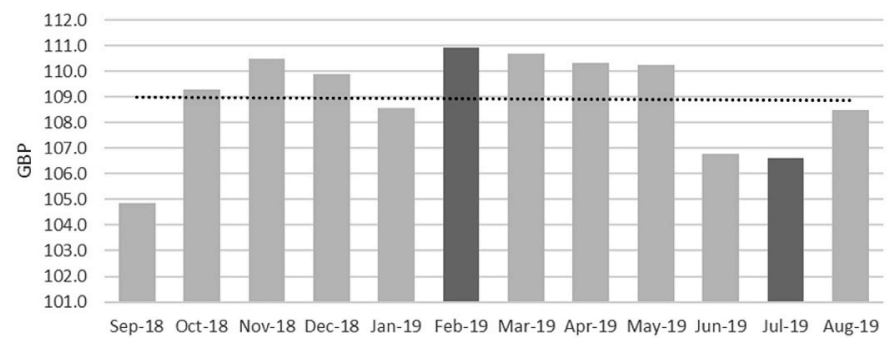

2018 and August 2019. Even though the overall number of listings does not change significantly over the year, some evidence of seasonality can be seen. For the purposes of our research, we chose the months of February and July to represent the off-peak and peak periods of activity, respectively. Thus, our datasets of Bristol Airbnb listings are dated February 9th and July 14th, 2019 and are sourced from the wellknown insideairbnb.com website that provides information from many cities all over the world, obtained by means of web-scraping from publicly-available sites. The combined dataset covers the whole population of 2337 listings featuring a wide variety of property types (from Villas to Campers) as well as room types. For the purposes of this research, we focus on the main two types of properties: apartments and houses, as well as the main two types of rooms (entire homes and private rooms). This leads to a subsample of 2056 listings. The spatial distribution of our July dataset is shown in Fig. 3. Clearly the city centre has a higher density of apartments, while the houses tend to appear in different clusters surrounding it. Tables 1 and 2 provide a breakdown of our peak and off-peak samples according to property and room type. Most of the apartments are rented as entire places, and the majority of houses offer private rooms. The price premium between entire homes and private rooms is evident from the average prices. Entire houses tend

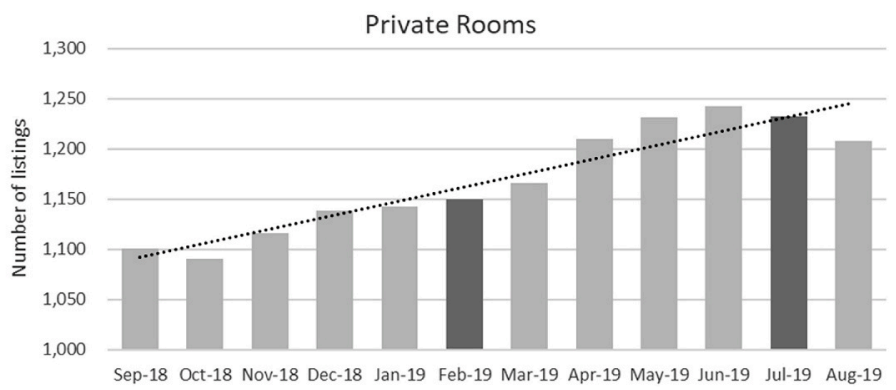

Private Rooms: avg. price per night

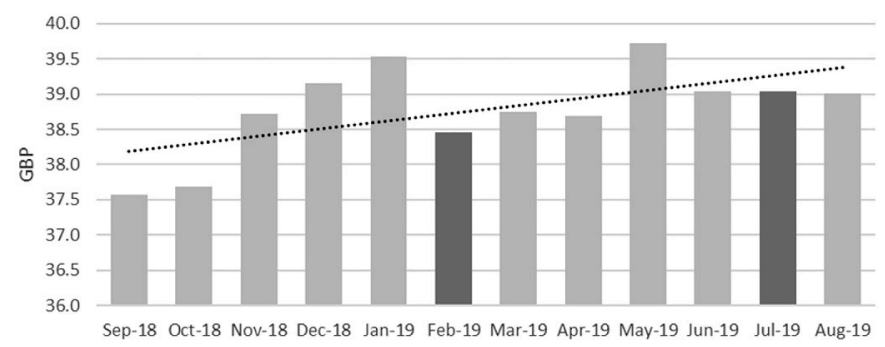

Fig. 2. Monthly distribution of Airbnb listings and average prices in Bristol (Sep-18 to Aug 19). Note: Vertical axes are truncated.

Source: www.insideairbnb.com 


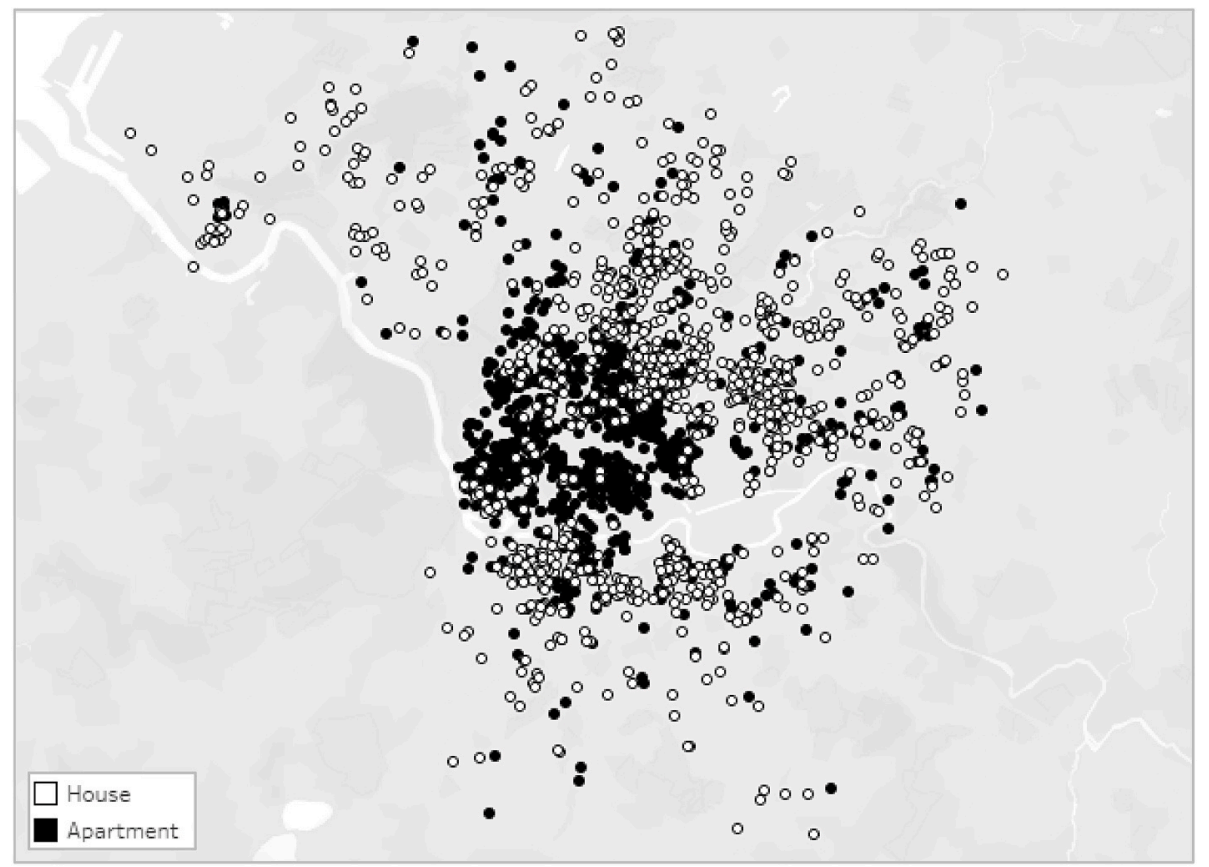

Fig. 3. Sample dataset of Airbnb listings (July 2019).

Sources: www.insideairbnb.com, mapbox, Openstreetmap

to be more expensive to rent than entire apartments, but, on the contrary, private rooms in apartments are pricier than their house counterparts. While the scraped data from insideairbnb.com is rich in both textual and quantitative information, we focus exclusively on numerical factors for our study. In line with the past literature, the selected variables relate to room prices, host characteristics, room features, and customer feedback.

The dataset is augmented with location factors for the individual listings, such as distance to the Bristol city center (located in the "Bristol Castle"), distance to the nearest bus stop, and distance to the nearest bus/train station. In addition, we also measured the number of tourism attractions within a $650 \mathrm{~m}$ radius of the listings, using the distance reference from Önder et al. (2018). All geospatial analysis was carried out in ArcGIS, and, for computational reasons, distances are computed "as the crow flies", which is the same approach used by past authors. The location of all the points of interest was sourced from openstreetmap.com, which also provides information about places of accommodation, food, and shopping. However, introducing additional location variables in our model was discarded after noting the high linear correlation with the "distance to city center" variable (Table 3).

\subsection{Methodology}

In order to investigate the drivers of Airbnb prices in Bristol, a set of ordinary least squares (OLS) hedonic price regression models are employed. For each period, nine OLS equations are estimated with different subsamples for each of the combinations of property type and room type (i.e. entire home, private room, apartment, houses, entireapartment, entire-house, room-apartment, room-house, and a final one with all observations). Two additional regressions per period are estimated with dummy variables for property/room types instead of separate samples. This detailed approach allows us to compare results and determine whether the prices of different property/room types have different determinants. The basic OLS specification is shown in

Table 1

Sample means of the chosen variables (February sample).

Sources: www.openstreetmap.com, www.insideairbnb.com, own elaboration

\begin{tabular}{|c|c|c|c|c|c|c|}
\hline \multirow[t]{2}{*}{ Property Type } & \multirow{2}{*}{$\begin{array}{l}\text { Variable } \\
\text { Name }\end{array}$} & \multicolumn{2}{|l|}{ Apartment } & \multicolumn{2}{|l|}{ House } & \multirow[t]{2}{*}{ Grand Total } \\
\hline & & Entire place & Private room & Entire place & Private room & \\
\hline No. of listings & - & 681 & 284 & 296 & 564 & 1825 \\
\hline Daily price per guest (GBP) & - & 79.93 & 44.71 & 104.29 & 38.28 & 65.53 \\
\hline Distance to nearest bus stop ( $\mathrm{km})$ & diststops & 0.13 & 0.14 & 0.17 & 0.16 & 0.15 \\
\hline Distance to city centre ( $\mathrm{km})$ & diststation & 1.69 & 1.79 & 2.63 & 2.97 & 2.25 \\
\hline Distance to nearest bus/train station $(\mathrm{km})$ & distcenter & 1.27 & 1.09 & 1.45 & 1.95 & 1.48 \\
\hline Host experience (days) & agehost & 1265.36 & 1473.85 & 1492.10 & 1773.09 & 1491.49 \\
\hline Host Listings & hostlisting & 7.61 & 1.48 & 1.44 & 2.05 & 3.93 \\
\hline Guest included & nguests & 1.74 & 1.10 & 2.87 & 1.09 & 1.62 \\
\hline Bathrooms & baths & 1.17 & 1.06 & 1.70 & 1.20 & 1.24 \\
\hline Bedrooms & bedrooms & 1.37 & 0.99 & 3.02 & 1.03 & 1.48 \\
\hline Maximum guest capacity & maxcap & 3.58 & 1.87 & 6.17 & 1.91 & 3.22 \\
\hline Annual Availability (days) & availyear & 145.03 & 107.64 & 84.24 & 129.53 & 124.56 \\
\hline No. of reviews & reviews & 34.95 & 28.64 & 14.38 & 36.36 & 31.07 \\
\hline Rating & rating & 85.23 & 78.04 & 73.19 & 80.73 & 80.77 \\
\hline No. of local tourism attractions & attractionsPOI & 69.53 & 55.70 & 20.78 & 18.40 & 43.67 \\
\hline
\end{tabular}


Table 2

Sample means of the chosen variables (July sample).

Sources: www.openstreetmap.com, www.insideairbnb.com, own elaboration

\begin{tabular}{|c|c|c|c|c|c|c|}
\hline \multirow[t]{2}{*}{ Property Type } & \multirow{2}{*}{$\begin{array}{l}\text { Variable } \\
\text { Name }\end{array}$} & \multicolumn{2}{|l|}{ Apartment } & \multicolumn{2}{|l|}{ House } & \multirow[t]{2}{*}{ Grand Total } \\
\hline & & Entire place & Private room & Entire place & Private room & \\
\hline No. of listings & - & 755 & 317 & 341 & 605 & 2018 \\
\hline Daily price per guest (GBP) & - & 80.10 & 44.70 & 105.18 & 37.57 & 65.58 \\
\hline Distance to nearest bus stop ( $\mathrm{km}$ ) & diststops & 0.14 & 0.15 & 0.18 & 0.17 & 0.16 \\
\hline Distance to city centre ( $\mathrm{km})$ & diststation & 1.71 & 1.80 & 2.63 & 3.01 & 2.27 \\
\hline Distance to nearest bus/train station ( $\mathrm{km})$ & distcenter & 1.27 & 1.09 & 1.44 & 1.97 & 1.48 \\
\hline Host experience (days) & agehost & 1271.28 & 1466.80 & 1620.17 & 1735.68 & 1500.18 \\
\hline Host Listings & hostlisting & 6.91 & 1.68 & 1.46 & 2.06 & 3.72 \\
\hline Guest included & nguests & 1.68 & 1.10 & 2.87 & 1.09 & 1.61 \\
\hline Bathrooms & baths & 1.17 & 1.06 & 1.71 & 1.19 & 1.25 \\
\hline Bedrooms & bedrooms & 1.38 & 0.99 & 3.04 & 1.03 & 1.50 \\
\hline Maximum guest capacity & maxcap & 3.56 & 1.86 & 6.18 & 1.90 & 3.24 \\
\hline Annual Availability (days) & availyear & 142.44 & 106.37 & 84.82 & 130.81 & 123.55 \\
\hline No. of reviews & reviews & 33.66 & 28.34 & 14.32 & 36.25 & 30.33 \\
\hline Rating & rating & 85.41 & 76.83 & 73.03 & 81.20 & 80.71 \\
\hline No. of local tourism attractions & attractionsPOI & 67.98 & 56.21 & 21.42 & 17.42 & 43.10 \\
\hline
\end{tabular}

Equation (1):

$$
\begin{aligned}
\ln (\text { priceperguest })= & \beta_{0}+\beta_{1} \text { diststops }+\beta_{2} \text { diststations }+\beta_{3} \text { distcenter } \\
& +\beta_{4} \text { agehost }+\beta_{5} \text { hostlisting }+\beta_{6} \text { nguest }+\beta_{7} \text { baths } \\
& +\beta_{8} \text { bedrooms }+\beta_{9} \text { maxcap }+\beta_{10} \text { availyear } \\
& +\beta_{11} \text { reviews }+\beta_{12} \text { rating }+\beta_{13} \text { attractionsPOI }+u
\end{aligned}
$$

where $u$ denotes the random error and $\beta$ is a vector of coefficients to be estimated.

We estimate a semilogarithmic model (as in Wang \& Nicolau, 2017) with the logged price per guest (priceperguest) as dependent variable. This refers to the number of guests included in the base price of the listing and includes the cleaning surcharge (as in Tong \& Gunter, 2020). The specification with dummy variables for property/room types just adds an interaction term to each coefficient.

The first set of explanatory variables looks at the distance between the listings and certain points of interest. The distance to the city center (distcenter) is the most common explanatory variable included in hedonic price studies of Airbnb listings, and also in the broader literature on hotel prices. It has been well established that the proximity of any type of accommodation offering to the city center, where most tourism attractions can usually be found, allows its owner to increase prices. Despite the strong negative correlation with distcenter, we also add a measure of the local density of tourism attractions (attractionsPOI) to capture any pricing power by host located close to attractions outside the city center. The distance to the nearest bus stop (diststops) and to the nearest bus station (diststations) aims to capture how accessible the listing is to the city's transportation network, which we hypothesize can enable the host to charge a price premium, even if the property is not in walking distance to the city center. Thus, all distance variables are expected to show negative signs, while the attractions variable should have a positive sign. As seen in Tables 1 and 2 as well as in Fig. 3, apartments are, on average, closer to the points of interest than the house listings.
The characteristics of the hosts can influence prices as well. We consider the host's "age" (agehost) as well as the total number of listings in the platform (hostlisting). The first was calculated as the difference between June 1st, 2020 (when the information was collected) and the date the host registered into Airbnb. This is expected to capture the ability of hosts that have more experience in the market to set better prices. The same level of experience can be presumed for hosts with multiple listings, which may also be able to exercise some degree of market power if they concentrate their properties within the same area. As seen in Tables 1 and 2, hosts that rent entire apartments are noticeably younger and have more listings than any of the other subgroups, which clearly suggests that corporate users may be using the platform to rent out entire buildings in a sort of "hidden" hotel operation. In any case, a positive sign is expected from both variables.

As room characteristics, we consider the number of guests included in the price (nguests), the number of bedrooms (bedrooms) and bathrooms (baths), the maximum guest capacity of the property (maxcap), and its annual availability in days (availyear). The first four are expected to have a positive impact, based on the conclusions of past studies, while the latter's impact on prices remains an open question. The model is completed with the total number of guest reviews accumulated by the property (reviews), as well as its average guest rating (rating). There is no consensus in the literature about their impact on prices.

Robust standard errors will be employed in order to account for the possible presence of heteroskedasticity and, in order to mitigate the risk of multicollinearity in the specifications, the variance inflation factors (VIFs) of al covariates will be checked post-estimation. The commonly used goodness-of-fit indicator (R-squared), the F-test of global significance of the model, as well as the Akaike Information Score (AIC) will provide the basis for the discussion of model performance.

After the OLS regressions confirm which types of listings are more sensitive to the selected variables, the second step is to spatially disaggregate the estimated coefficients for a more detailed picture of price

\begin{tabular}{|c|c|c|c|c|c|}
\hline & Distance to Center & Accomodation & Attractions & Food/Shopping & Airbnb Listings \\
\hline Distance to Center & 1.000 & & & & \\
\hline AccommodationPOI & -0.590 & 1.000 & & & \\
\hline AttractionsPOI & -0.642 & 0.899 & 1.000 & & \\
\hline Food/ShoppingPOI & -0.692 & 0.886 & 0.830 & 1.000 & \\
\hline Airbnb Listings & -0.751 & 0.545 & 0.634 & 0.701 & 1.000 \\
\hline
\end{tabular}

Table 3

Linear correlation between location variables.

Source: own elaboration 
effects. This is achieved by means of a geographically-weighted regression (GWR), with the same structure as the OLS one:

$$
\begin{aligned}
\ln (\text { priceperguest })= & \beta_{0 i}+\beta_{1 i} \text { diststops }+\beta_{2 i} \text { diststations }+\beta_{3 i} \text { distcenter } \\
& +\beta_{4 i} \text { agehost }+\beta_{5 i} \text { hostlisting }+\beta_{6 i} \text { nguest }+\beta_{7 i} \text { baths } \\
& +\beta_{8 i} \text { bedrooms }+\beta_{9 i} \text { maxcap }+\beta_{10 i} \text { availyear } \\
& +\beta_{11 i} \text { reviews }+\beta_{12 i} \text { rating }+\beta_{13 i} \text { attractionsPOI }+u
\end{aligned}
$$

$\beta_{i}$ now denotes a vector of coefficients specific to location $i$ that need to be estimated. The GWR process is essentially a weighted regression that employs a spatial weighting matrix $\left(W_{i j}\right)$ calculated with a Gaussian function that can be expressed as:

$W_{i j}=\exp \left(-0.5\left(\frac{d_{i j}}{b}\right)^{2}\right)$

where $d_{i j}$ denotes the distance between a listing's own location $(i)$ and the location of all other listings in the sample (j), and $b$ refers to a distance "bandwidth", which is determined by means of an iterative optimization process that aims to minimize the model's AIC score. Since the GWR returns estimation coefficients for each individual location, displaying the results in a map allows us to evaluate any underlying geographical patterns in regard to the influence of the selected variables on prices. Robust standard errors are also employed here. The calculations were carried out in ArcMap 10.4.1 using its spatial statistics toolbox.

\section{Results and discussion}

The estimated coefficients from the OLS hedonic price equations for the peak July sample are shown in Table 4, while the February results are provided in Appendix A. The VIFs of all variables were below 3.6 in all cases, which is an acceptable range that allows us to discard any potential multicollinearity problems. The first conclusion that can be drawn from these estimates is that combining different property and room types in the same price equation (as many past authors have done) may not be a good approach. When disaggregating the sample of listings, it is clear that the established price drivers mentioned by past studies (location, room and host characteristics) are more relevant for listings offering entire properties than for private rooms. This is evident from the sharply different levels of goodness-of-fit, with the house and apartment-room equations achieving $11 \%$ and $17 \%$ R-squared values, in contrast with the $30-56 \%$ from the entire-property equations. This conclusion is robust to alternative time periods, as shown by the February results in Appendix A, as well as to alternative dependent variables, such as the price per maximum guest capacity.

We offer two interpretations for this result: first, a possible nontourism use of room listings, which implies that Airbnb is penetrating other types of residential markets with different locational factors to consider. However, we ran an alternative specification with the variables typically used to explain house and rental prices (such as the proximity to schools/universities, hospitals, income per capita, or the density of crime in the neighbourhood, as in Lawani et al., 2019) without a significant improvement in goodness-of-fit. In view of that, another possible explanation is the implementation of dynamic pricing strategies by hosts (Magno et al., 2018), similar to the second-degree price discrimination used by hotels. These practices can include discounts based on the time between the booking and the guest arrival date with the goal of maximizing revenues by facilitating the self-selection of guests with different price elasticities of demand. A consequence of these practices is that the underlying decision-making process for setting prices is too complex to be modelled with our chosen methods and much more detailed (i.e. transaction-level) data is required before being able to capture these effects in the model. This can also explain the noticeable drop in overall goodness-of-fit between peak and off-peak specifications, with the more complex peak pricing strategies dragging down model performance.

The results from Table 4 already show differences in the estimated price effects between different subsamples of listings. These differences are better illustrated by Table 5, which shows the results for the same basic specification complemented with dummy variables of property and room type. Both peak and off-peak models are shown. The intercept-level dummies that aim to capture the magnitude of the price premium between entire homes and private rooms (the approach used in past studies) are now insignificant, since our specification aims to explain the price differences in relation to the listing's intrinsic char-

\begin{tabular}{|c|c|c|c|c|c|c|c|c|c|c|c|c|c|c|c|c|c|c|}
\hline July & All obs & & Room & & Entire & & House & & Apartment & & Room & & Room & & Entire & & Entire & \\
\hline \multirow[t]{2}{*}{ Sample } & & & & & & & & & & & House & & Apartment & & House & & Apartment & \\
\hline & Coef. & & Coef. & & Coef. & & Coef. & & Coef. & & Coef. & & Coef. & & Coef. & & Coef. & \\
\hline diststops & 0.6293 & $*$ & 0.3199 & & 0.6481 & * & 0.4591 & & 0.5622 & $*$ & 0.3038 & & 0.3764 & & 0.8836 & & 0.4675 & \\
\hline diststation & -0.0436 & $*$ & -0.0414 & & -0.0594 & & -0.0321 & & -0.0566 & & -0.0430 & & -0.0397 & & 0.0702 & & -0.1384 & * \\
\hline distcenter & -0.0367 & & -0.0352 & & 0.0338 & & -0.0202 & & 0.0012 & & -0.0365 & & -0.0313 & & -0.0253 & & 0.0923 & \\
\hline agehost & $-1.3 \mathrm{E}-05$ & $*$ & $-9.4 \mathrm{E}-06$ & * & $-4.4 \mathrm{E}-06$ & & $-9.0 \mathrm{E}-06$ & & $-6.8 \mathrm{E}-05$ & & $-1.0 \mathrm{E}-05$ & $*$ & $-1.9 \mathrm{E}-05$ & & $-4.2 \mathrm{E}-06$ & & $-2.1 \mathrm{E}-05$ & \\
\hline hostlisting & 0.0033 & $*$ & 0.0155 & * & 0.0014 & & -0.0186 & & 0.0042 & $*$ & -0.0104 & & 0.0248 & $*$ & 0.0746 & & 0.0014 & \\
\hline nguests & -0.3415 & $*$ & -0.4984 & * & -0.3293 & $*$ & -0.3197 & * & -0.3882 & $*$ & -0.4514 & $*$ & -0.5941 & $*$ & -0.3278 & * & -0.3522 & * \\
\hline baths & 0.0280 & & -0.0298 & & 0.2607 & * & 0.0199 & & 0.2933 & $*$ & 0.0132 & & 0.2333 & & 0.1306 & $*$ & 0.3853 & * \\
\hline bedrooms & 0.1438 & $*$ & 0.0937 & & 0.1303 & $*$ & 0.1845 & * & 0.0867 & & 0.0661 & & 0.3664 & & 0.0825 & & 0.1237 & * \\
\hline maxcap & 0.2023 & $*$ & 0.2022 & * & 0.0815 & $*$ & 0.2103 & $*$ & 0.1482 & $*$ & 0.1777 & $*$ & 0.2751 & $*$ & 0.1437 & * & 0.0382 & \\
\hline availyear & 0.0005 & $*$ & 0.0005 & * & 0.0008 & $*$ & 0.0004 & & 0.0007 & $*$ & 0.0006 & $*$ & 0.0005 & & 0.0009 & & 0.0008 & * \\
\hline reviews & -0.0013 & $*$ & -0.0021 & * & 0.0002 & & -0.0020 & * & 0.0001 & & -0.0018 & $*$ & -0.0018 & $*$ & -0.0013 & & 0.0006 & \\
\hline rating & -0.0008 & & -0.0009 & & -0.0015 & $*$ & -0.0019 & $*$ & 0.0004 & & -0.0013 & & 0.0001 & & -0.0017 & & -0.0011 & \\
\hline attractionsPOI & 0.0018 & $*$ & 0.0019 & * & 0.0008 & & 0.0018 & & 0.0008 & & 0.0000 & & 0.0014 & & 0.0030 & & 0.0011 & \\
\hline constant & 3.8358 & & 3.9621 & & 4.1401 & & 3.7125 & & 3.8750 & & 4.0190 & & 3.3969 & & 3.9470 & & 4.1496 & \\
\hline Number of obs & 2018 & & 922 & & 1096 & & 946 & & 1072 & & 605 & & 317 & & 341 & & 755 & \\
\hline $\boldsymbol{F}$ & 96.71 & & 14.84 & & 59.83 & & 69.07 & & 29.1 & & 6.96 & & 13.56 & & 43.16 & & 25.27 & \\
\hline Prob $>F$ & 0 & & 0 & & 0 & & 0 & & 0 & & 0 & & 0 & & 0 & & 0 & \\
\hline$R$-squared & 0.35 & & 0.14 & & 0.40 & & 0.48 & & 0.24 & & 0.11 & & 0.17 & & 0.56 & & 0.30 & \\
\hline$A I C$ & 4345.34 & & 1827.00 & & 2241.57 & & 1989.42 & & 2240.93 & & 1204.07 & & 628.03 & & 729.99 & & 1493.73 & \\
\hline
\end{tabular}
acteristics. In that regard, the most relevant conclusion relates to the

Table 4

OLS regression results: separate samples (July).

Note: * indicates that the coefficient is significant at $5 \%$ level. 
Table 5

OLS regression results: joint samples.

\begin{tabular}{|c|c|c|c|c|c|c|c|c|c|}
\hline \multirow[t]{2}{*}{ Property Type } & \multicolumn{2}{|l|}{ February } & \multicolumn{2}{|l|}{ July } & \multirow[t]{2}{*}{ Room Type } & \multicolumn{2}{|l|}{ February } & \multicolumn{2}{|l|}{ July } \\
\hline & Coef. & & Coef. & & & Coef. & & Coef. & \\
\hline diststops & 0.5052 & $*$ & 0.5993 & $*$ & diststops & 0.7473 & $*$ & 0.6848 & * \\
\hline$($ House $=1)$ & 0.1186 & & -0.1990 & & $($ Room $=1)$ & -0.1893 & & -0.4142 & \\
\hline diststation & -0.0017 & & -0.0613 & & diststation & 0.0272 & & -0.0604 & \\
\hline (House $=1)$ & -0.0233 & & 0.0292 & & $($ Room $=1)$ & -0.0522 & $*$ & 0.0203 & \\
\hline distcenter & -0.0060 & & 0.0142 & & distcenter & -0.0287 & & 0.0411 & \\
\hline$($ House $=1)$ & -0.0153 & & -0.0419 & & $($ Room $=1)$ & 0.0134 & & -0.0819 & \\
\hline agehost & 0.0000 & & -0.0001 & & agehost & 0.0000 & & 0.0000 & \\
\hline (House $=1$ ) & 0.0000 & & 0.0000 & & $($ Room $=1)$ & 0.0000 & & 0.0000 & \\
\hline host_listi & 0.0037 & $*$ & 0.0042 & $*$ & host_listi & 0.0058 & $*$ & 0.0014 & \\
\hline (House $=1$ ) & -0.0038 & & -0.0250 & & $($ Room $=1)$ & -0.0116 & & 0.0137 & \\
\hline nguests & -0.3269 & $*$ & -0.3887 & $*$ & nguests & -0.3864 & $*$ & -0.3300 & * \\
\hline (House $=1$ ) & -0.3022 & * & 0.0692 & & $($ Room $=1)$ & 0.0703 & $*$ & -0.1986 & * \\
\hline baths & 0.2127 & $*$ & 0.3050 & $*$ & baths & 0.2459 & $*$ & 0.2642 & * \\
\hline (House $=1$ ) & -0.2435 & $*$ & -0.2918 & $*$ & $($ Room $=1)$ & -0.2626 & $*$ & -0.3080 & * \\
\hline bedrooms & 0.1269 & $*$ & 0.0901 & & bedrooms & 0.1248 & $*$ & 0.1321 & * \\
\hline$($ House $=1)$ & -0.1669 & $*$ & 0.0900 & & $($ Room $=1)$ & 0.0347 & & -0.0711 & \\
\hline maxcap & 0.0832 & $*$ & 0.1487 & $*$ & maxcap & 0.1578 & * & 0.0822 & * \\
\hline$($ House $=1)$ & 0.1328 & $*$ & 0.0626 & $*$ & $($ Room $=1)$ & 0.0308 & & 0.1218 & * \\
\hline availy & 0.0005 & $*$ & 0.0007 & $*$ & availy & 0.0005 & $*$ & 0.0008 & * \\
\hline$($ House $=1)$ & 0.0001 & & -0.0003 & & $($ Room $=1)$ & -0.0002 & & -0.0003 & \\
\hline reviews & -0.0010 & $*$ & 0.0000 & & reviews & -0.0005 & $*$ & 0.0002 & \\
\hline$($ House $=1)$ & 0.0002 & & -0.0021 & $*$ & $($ Room $=1)$ & -0.0007 & & -0.0023 & * \\
\hline rating & -0.0002 & & 0.0006 & & rating & 0.0006 & & -0.0014 & * \\
\hline (House $=1$ ) & 0.0003 & & -0.0026 & $*$ & $($ Room $=1)$ & -0.0008 & & 0.0004 & \\
\hline attractionsPOI & 0.0012 & $*$ & 0.0010 & & attractionsPOI & 0.0012 & * & 0.0009 & \\
\hline$($ House $=1)$ & 0.0006 & & 0.0004 & & $($ Room $=1)$ & 0.0004 & & 0.0008 & \\
\hline constant & 3.8610 & $*$ & 3.7849 & $*$ & constant & 3.4810 & * & 4.0841 & * \\
\hline (House $=1)$ & -0.2553 & $*$ & -0.1625 & & $($ Room $=1)$ & 0.0683 & & -0.1780 & \\
\hline Number of obs & 1825 & & 2018 & & Number of obs & 1825 & & 2018 & \\
\hline$F$ & 171.62 & & 61.14 & & $F$ & 128.32 & & 80.46 & \\
\hline Prob $>F$ & 0 & & 0 & & Prob $>F$ & 0 & & 0 & \\
\hline$R$-squared & 0.700 & & 0.394 & & $R$-squared & 0.623 & & 0.440 & \\
\hline$A I C$ & 1338.18 & & 4229.40 & & AIC & 1755.72 & & 4068.74 & \\
\hline
\end{tabular}

Note: * indicates that the coefficient is significant at $5 \%$ level.

bathroom variable, which is a positive and significant price determinant for entire properties and apartments, but its relevance for houses and private rooms is much reduced. This agrees with the results by Lopez at al. (2020) for room types, which we now extend to property types as well. In regard to bedrooms, the only significant difference appears between apartments and houses in the off-peak period, possibly as a result of a more accentuated split between visitor segments in relation to group size. The overall size of the property (proxied by its maximum capacity) is significantly more important for houses than apartments, again due to the likely difference in group size requirements. Also, room capacity is only significantly more relevant than the capacity of an entire property during the peak period. None of the other location, host, or quality characteristics were found to differ across room and property types. We ran additional regressions separating between downtown and outskirts properties, as well as an alternative quadratic specification for the "distance to city centre" variable, without any major difference in the conclusions of the OLS models.

Additional insights on the location aspects is provided by the GWR analysis. Only two subsets of data (entire apartments and entire houses) are used in this stage due to their higher goodness-of-fit in relation to private room listings. The results for July are shown in Table 6. The basic specification is the same as above, but the GWR equations show better performance than the OLS counterparts, as indicated by the lower value for AIC and higher R-squared coefficients (in agreement with Soler \& Gemar, 2018 and Zhang et al., 2017). Since coefficients are available for each sample location, the significance of the estimated price effects is evaluated at the mean of the standard deviation estimates.

Overall, the house specification presents more coefficients that are significant at $5 \%$ level, but, when looking at the disaggregated results, both equations reveal spatial patterns in the sensitivity of prices to room features or location. Fig. 4 and Appendix B show the deviation of the location-specific coefficients with respect to the averages in Table 6. For ease of visualization, the deviations are classified in three categories ( $-5 \%$ or less, between $-5 \%$ and $5 \%, 5 \%$ or more).

Prices per guest for apartments are positively (and significantly) influenced by their distance to bus stops, while, for houses, there is a positive relationship with distance to transport stations. This is an unexpected result (in relation to past studies) that may indicate that proximity to main roads is an undesirable characteristic, possibly due to noise concerns. This argument is also supported by the fact that, with a dense network of bus routes and stops, the variability in distances is not large across listings in Bristol. In fact, 95\% of the sample is located closer than $300 \mathrm{~m}$ from the nearest bus stop so it is difficult from hosts to derive enough competitive advantage from this factor to warrant a price premium. From a location perspective (Appendix A), it is interesting to note that, while for apartments the impact of the distance to bus stops is different between properties east and west from the city centre, the impact of the same variable for houses presents a sharp north-south divide instead.

The distance to the city centre coefficient only has the expected negative coefficient for house listings, which is further confirmed by the positive impact of the proximity to tourist attractions (as in Önder et al., 2018). As seen in Fig. 3, the distance effect is more negative for the house listings in the western neighbourhoods. This means that, the farther away the properties stand from the city centre towards the sea, the more relevant the proximity factor becomes at the time of setting prices. Interestingly, this effect is reversed in the Shirehampton and Avonmouth areas closer to the Port and largely separated from the rest of Bristol. 
Table 6

GWR results (July).

\begin{tabular}{|c|c|c|c|c|c|c|c|c|c|c|}
\hline \multirow[t]{2}{*}{ Coeff. } & \multicolumn{5}{|c|}{ Entire Apartment } & \multicolumn{5}{|c|}{ Entire House } \\
\hline & mean & & $\min$. & median & $\max$ & mean & & $\min$. & median & $\max$ \\
\hline diststops & 0.432 & $*$ & -0.296 & 0.430 & 1.165 & 1.041 & & 0.849 & 1.036 & 1.193 \\
\hline diststation & -0.105 & & -0.283 & -0.105 & -0.063 & 0.075 & $*$ & 0.054 & 0.075 & 0.248 \\
\hline distcenter & 0.073 & & -0.033 & 0.072 & 0.264 & -0.018 & $*$ & -0.147 & -0.018 & 0.037 \\
\hline agehost & 0.000 & & 0.000 & 0.000 & 0.000 & 0.000 & * & 0.000 & 0.000 & 0.000 \\
\hline hostlisting & 0.002 & & 0.001 & 0.002 & 0.002 & 0.058 & $*$ & 0.046 & 0.058 & 0.113 \\
\hline nguests & -0.353 & & -0.376 & -0.354 & -0.330 & -0.324 & $*$ & -0.345 & -0.325 & -0.319 \\
\hline baths & 0.391 & $*$ & 0.353 & 0.392 & 0.421 & 0.119 & * & 0.069 & 0.120 & 0.132 \\
\hline bedrooms & 0.144 & $*$ & -0.011 & 0.144 & 0.169 & 0.051 & $*$ & 0.037 & 0.051 & 0.162 \\
\hline maxcap & 0.031 & $*$ & 0.028 & 0.031 & 0.062 & 0.154 & $*$ & 0.119 & 0.155 & 0.160 \\
\hline availyear & 0.001 & $*$ & 0.001 & 0.001 & 0.001 & 0.001 & $*$ & 0.001 & 0.001 & 0.001 \\
\hline reviews & 0.001 & & 0.000 & 0.001 & 0.002 & -0.001 & * & -0.002 & -0.001 & 0.000 \\
\hline rating & -0.001 & & -0.002 & -0.001 & -0.001 & -0.001 & $*$ & -0.005 & -0.001 & 0.000 \\
\hline attractionsPOI & 0.001 & & -0.001 & 0.001 & 0.003 & 0.003 & $*$ & 0.002 & 0.003 & 0.004 \\
\hline constant & 4.136 & $*$ & 3.968 & 4.168 & 4.705 & 3.909 & * & 3.829 & 3.910 & 4.212 \\
\hline Number of obs & 755 & & & & & 341 & & & & \\
\hline R-squared & 0.325 & & & & & 0.593 & & & & \\
\hline AIC & 1480.59 & & & & & 718.60 & & & & \\
\hline
\end{tabular}

Note: * indicates that the coefficient is significant at $5 \%$ level.

The experience of the hosts (i.e. their "age") is only a significant price determinant for houses. This result, which was not found to be significant by Zhang et al. (2017), can be linked to the fact that house hosts have been, on average, more time in the platform and hence can better leverage their superior knowledge of the local market and the dynamics of price and demand. As expected, the hosts that offer multiple house listings charge higher prices (as concluded by Kwok \& Xie, 2019). This signals the existence of market power that has been traditionally associated with market concentration. Indeed, if many properties in the same area are owned by the same person, the intensity of competition is reduced, which facilitates price coordination across properties. The likelihood of collusion between multiple-listing hosts in the same area also increases with the lack of independent operators and significant capacity constraints in periods of strong demand, such as during the summer period. While these practices can distort the freemarket equilibrium that one can expect from "sharing-economy" markets, the ability of competition authorities to prosecute collusion in these types of platforms is still an open debate. In any case, the results of our GWR model reveal a higher degree of market power in the more affluent neighbourhoods northwest of the city centre. An interesting implication for single-house hosts in those areas is that, if they know about the presence of multiple-listing hosts in their area, they should be able to charge higher prices as well due to a reduced intensity of spatial competition, which, in a context of a perishable product (room nights) can potentially be very fierce (Masiero et al., 2015).

The price sensitivity of room features, which has been thoroughly analysed by past studies with joint samples, can also be differentiated according to property type. While the number of bathrooms is always a relevant factor for both types of properties. The spatial distribution of the estimated coefficients shown in Table 4, reveals that bathrooms are more relevant price drivers for apartments in the southeast while, for houses, the largest effects are seen right in the city centre, becoming less relevant in the outskirts properties. The number of bedrooms is a positive and significant driver for both types of listings as well, but again, the spatial variability (Appendix A) indicates that, while additional bedrooms are clearly more valuable for city-centre apartments, the opposite applies to houses, where a higher number of bedrooms drives up higher rates in the outskirts. This is a signal that guest preferences can be clearly segmented across property types and locations (similarly to the traditional accommodation markets) and this, again, warrants the disaggregated approach.

The prices of houses and apartments are positively influenced by their annual availability, which can also be interpreted from the perspective of repeat visitors (tourism and non-tourism ones), which can derive loyalty to certain hosts and properties (and hence a willingness to pay higher prices) from their ability to book the same place at different times of year. The GWR results clearly show that outskirts properties benefit more from their extended availability than the citycentre ones. The negative impact of the number of reviews and rating for houses (similarly to Wang \& Nicolau, 2017) and the lack of significance of for the apartments indicate that reputational aspects are secondary to room attributes as price determinants (Chen \& Xie, 2017).

In view of the above, our results clearly show that different property and room types may not have the same price determinants and that these effects can vary depending on location or the period in which the property is listed. Besides the pricing implications detailed above, this also raises a key methodological recommendation for future studies: rather than specifying property or room-type dummies in hedonic price equations, it is recommended either to break down the sample of listings according to room and property types, or, alternatively, specify several interactions between the price effects and the type of listing. Since the existence of differentiated drivers of price hints at an underlying segmentation of visitor profiles, this aspect should be taken into account in spatial competition models to property characterize the competition that Airbnb listings exert among themselves, with the impact of proximity inevitably moderated by the similarity in property/ room type characteristics.

\section{Summary}

\subsection{Main findings}

This paper presents a study about the drivers of Airbnb prices in Bristol (United Kingdom), with focus on the differences between locations, property types (apartments vs houses), and room types (entire homes vs private rooms). To that end, we employ a web-scraped dataset of 2056 Airbnb listings to estimate a set of hedonic price equations by means of ordinary least squares (OLS) and geographically-weighted regression (GWR) methods.

The exploration of the data reveals several key differences in location, host, and room characteristics between houses and apartments that raise the question whether their prices are driven by the same factors. This is confirmed by the sharply different levels of goodness-offit between the OLS models of entire homes and private rooms, hinting at a possible non-tourism use of some of these properties. In relation to property types, we find statistically significant differences in the price 


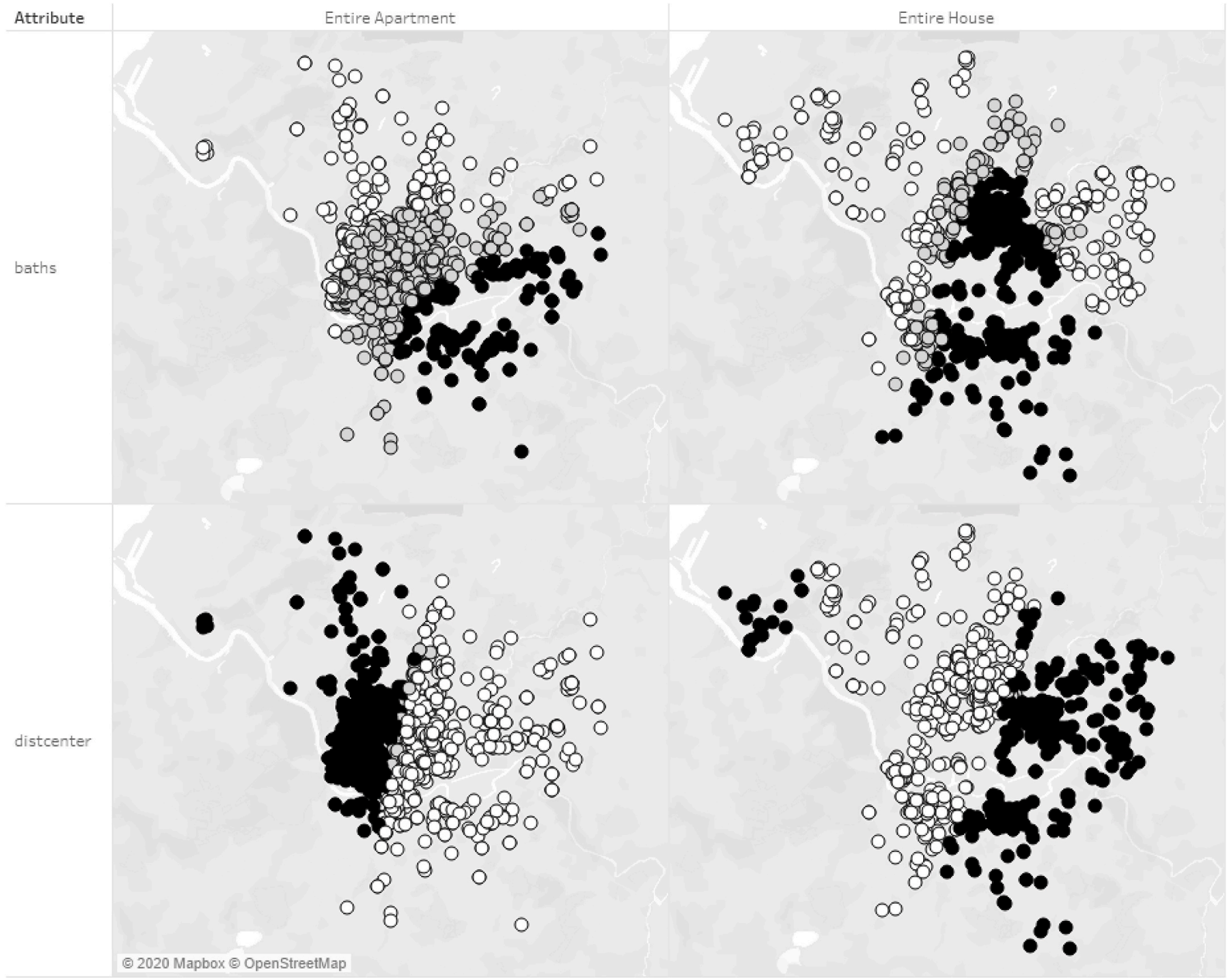

Dev. from avg. coeff.

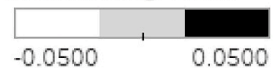

Fig. 4. Spatial distribution of the GWR estimated coefficients: baths and distcenter (July Sample).

effects of additional bathrooms, bedrooms, and guest capacities, though the last two only in off-peak and peak periods, respectively.

The GWR estimation results reveal that "distance to city centre" only affects the price of house listings, particularly in western areas. On the contrary, all outskirts listings appear to drive a price premium from extended annual availability, hinting at a higher ability to elicit visitor loyalty. Also, the highest-income neighbourhoods north of the city centre afford a higher degree of market power to hosts with multiple listings, which could also be exploited by single-listing hosts if they are aware of the reduced level of spatial competition associated with the increased market concentration in the area.

Besides the pricing implications for Airbnb hosts enumerated above, we conclude with two methodological recommendations for future studies. First, estimating separate price coefficients according to property/room type is a superior approach than just introducing a single dummy to estimate a price premium. Secondly, the underlying differences in visitor profiles that drive this heterogeneity also should be accounted for in spatial competition models by allowing for listings of the same type to exert a stronger competitive constraint than listings of different types at the same levels of proximity.

\subsection{Limitations and future research}

The conclusions of this paper should be taken with caution since our results are heavily location-specific, not only in relation to the type of hosts and guests in the Bristol market and their preferences, but also in relation to its unique spatial heterogeneity in terms of city layout, sociodemographic and transportation networks. Alternative methodologies, such as propensity-score matching, could also be used to investigate further the different market regimes within the city, which can be as narrow as a neighbourhood and as wide as the city itself. While outside the scope of this paper, it would also be of great interest to investigate the price determinants for private rooms in Bristol as this can shed light on any potential non-tourism uses for these properties that uncover an extended impact of Airbnb in the city beyond the short-term tourism rentals market. This can have implications for public authorities in a context of high concern about the impact these "sharing economy" platforms can have on residential markets. 


\section{Appendix A. Supplementary data}

Supplementary data to this article can be found online at https:// doi.org/10.1016/j.jhtm.2020.08.015.

\section{References}

Becerra, M., Santaló, J., \& Silva, R. (2013). Being better vs. being different: Differentiation, competition, and pricing strategies in the Spanish hotel industry. Tourism Management, 34, 71-79.

Blal, I., Singal, M., \& Templin, J. (2018). Airbnb's effect on hotel sales growth. International Journal of Hospitality Management, 73, 85-92.

Boros, L., Dudás, G., Kovalcsik, T., Papp, S., \& Vida, G. (2018). Airbnb in Budapest: Analysing spatial patterns and room rates of hotels and peer-to-peer accommodations. Geojournal of Tourism and Geosites, 21(1), 26-38.

Chattopadhyay, M., \& Mitra, S. (2020). What Airbnb host listings influence peer-to-peer tourist accommodation price? Journal of Hospitality \& Tourism Research, 44(4), 597-623.

Chen, C. F., \& Rothschild, R. (2010). An application of hedonic pricing analysis to the case of hotel rooms in Taipei. Tourism Economics, 16, 685-694.

Chen, Y., \& Xie, K. L. (2017). Consumer valuation of airbnb listings: A hedonic pricing approach. International Journal of Contemporary Hospitality Management, 29(9), 2405-2424.

Dogru, T., Mody, M., \& Suess, C. (2019). Adding evidence to the debate: Quantifying Airbnb's disruptive impact on ten key hotel markets. Tourism Management, 72, 27-38.

Dudás, G., Boros, L., Kovalcsik, T., \& Kovalcsik, B. (2017). The visualization of the spatiality of airbnb in budapest using 3-band raster representation. Geographia Technica, 12(1), 23-30.

Eugenio-Martin, J. L., Cazorla-Artiles, J. M., \& González-Martel, C. (2019). On the determinants of Airbnb location and its spatial distribution. Tourism Economics, 25(8), 1224-1244.

Fotheringham, A. S., Crespo, R., \& Yao, J. (2015). Exploring, modelling and predicting spatiotemporal variations in house prices. The Annals of Regional Science, 54(2), 417-436.

Gibbs, C., Guttentag, D., Gretzel, U., Morton, J., \& Goodwill, A. (2018). Pricing in the sharing economy: A hedonic pricing model applied to airbnb listings. Journal of Travel \& Tourism Marketing, 35(1), 46-56.

Gunter, U., \& Önder, I. (2018). Determinants of Airbnb demand in Vienna and their implications for the traditional accommodation industry. Tourism Economics, 24(3), 270-293.

ITV. Pressure on Bristol city council to introduce air BNB exclusion zones. (2018). 08/08/ 2018. Available at: https://www.itv.com/news/westcountry/2018-08-08/pressureon-bristol-city-council-to-introduce-air-bnb-exclusion-zones Accessed on 23/08/ 2020 .

Kwok, L., \& Xie, K. L. (2019). Pricing strategies on Airbnb: Are multi-unit hosts revenue pros? International Journal of Hospitality Management, 82, 252-259.

Lawani, A., Reed, M. R., Mark, T., \& Zheng, Y. (2019). Reviews and price on online platforms: Evidence from sentiment analysis of Airbnb reviews in Boston. Regional Science and Urban Economics, 75, 22-34.

López, F., Mínguez, R., \& Mur, J. (2020). ML versus IV estimates of spatial SUR models: Evidence from the case of airbnb in madrid urban area. The Annals of Regional Science, (64), 313-347 2020 .

Lorde, T., Jacob, J., \& Weekes, Q. (2019). Price-setting behavior in a tourism sharing economy accommodation market: A hedonic price analysis of AirBnB hosts in the caribbean. Tourism Management Perspectives, 30, 251-261.

Lutz, C., \& Newlands, G. (2018). Consumer segmentation within the sharing economy: The case of Airbnb. Journal of Business Research, 88, 187-196.

Magno, F., Cassia, F., \& Ugolini, M. M. (2018). Accommodation prices on airbnb: Effects of host experience and market demand. TQM Journal, 30(5), 608-620.

Masiero, L., Nicolau, J. L., \& Law, R. (2015). A demand-driven analysis of tourist accommodation price: A quantile regression of room bookings. International Journal of Hospitality Management, 50, 1-8.

Mccord, M., Davis, P. T., Haran, M., Mcgreal, S., \& Mcilhatton, D. (2012). Spatial variation as a determinant of house price: Incorporating a geographically weighted regression approach within the Belfast housing market. Journal of Financial Management of Property and Construction, 17(1), 49-72.

Önder, I., Weismayer, C., \& Gunter, U. (2018). Spatial price dependencies between the traditional accommodation sector and the sharing economy. Tourism Economics, 25(8), 1150-1166.

Perez-Sanchez, V. R., Serrano-Estrada, L., Marti, P., \& Mora-Garcia, R.-T. (2018). The what, where, and why of airbnb price determinants. Sustainability, 10(12), Article 4596.

Schamel, G. (2012). Weekend vs. midweek stays: Modelling hotel room rates in a small market. International Journal of Hospitality Management, 31, 1113-1118.

Soler, I. P., \& Gemar, G. (2018). Hedonic price models with geographically weighted regression: An application to hospitality. Journal of Destination Marketing and Management, 9, 126-137.

Suárez-Vega, R., \& Hernández, J. (2020). Selecting prices determinants and including spatial effects in peer-to-peer accommodation. International Journal of Geo-information, 9259.

Tong, B., \& Gunter, U. (2020). Hedonic pricing and the sharing economy: How profile characteristics affect airbnb accommodation prices in Barcelona, Madrid, and Seville. Current Issues in Tourism. https://doi.org/10.1080/13683500.2020.1718619.

Wang, D., \& Nicolau, J. L. (2017). Price determinants of sharing economy-based ac commodation rental: A study of listings from 33 cities on Airbnb.com. International Journal of Hospitality Management, 62, 120-131.

Xie, K. L., \& Kwok, L. (2017). The effects of Airbnb's price positioning on hotel performance. International Journal of Hospitality Management, 67, 174-184.

Yang, Y., Mueller, N. J., \& Croes, R. R. (2016). Market accessibility and hotel prices in the Caribbean: The moderating effect of quality-signaling factors. Tourism Management, $56,40-51$.

Yao, J., \& Fotheringham, A. (2016). Local spatiotemporal modeling of house prices: A mixed model approach. The Professional Geographer, 68(2), 189-201.

Zhang, Z., Chen, R., Han, L., \& Yang, L. (2017). Key factors affecting the price of airbnb listings: A geographically weighted approach. Sustainability, 9(9), Article 1635. 